\title{
Anomalous Palmaris Longus Tendon Causing Carpal Tunnel Syndrome
}

\author{
Harsh R. Shah ${ }^{1,} \quad$ Amita Hiremath ${ }^{1} \quad$ Mukund R. Thatte
}

Address for correspondence Mukund R. Thatte, $\mathrm{MCh}$, Department of Plastic Surgery, Bombay Hospital and Institute of Medical Sciences, Room 6, $2^{\text {nd }}$ Floor, New Wing, Marine Lines, Mumbai 400020, Maharashtra, India (e-mail: mthatte@gmail.com).

on to the palmar aponeurosis distally but from within the tunnel. Also, the median nerve appeared to be compressed significantly. The tendon was released from the ulnar side attachments to the palmar aponeurosis, thus impairing its ability to compress and making it a part of the radial leaf of the roof of the tunnel. Median nerve epineurotomy was performed. The carpal tunnel release was continued proximally in the distal deep fascia of the forearm. After verifying adequate release of the median nerve both proximally and distally, the incision was closed.

PL is one of the most variable muscles in the human body. It is a slender fusiform muscle arising from the medial epicondyle as a part of the common flexor tendon and also from the adjacent intermuscular septa and the antebrachial fascia. The tendinous structure normally passes anterior to the flexor retinaculum and then distally continues with the palmar aponeurosis ${ }^{2}$ (-Fig. 2). This topographic relationship of the tendon with the median nerve makes its anatomical variations a common cause of median nerve entrapment. Several anatomical variations of the PL muscle have been studied in the past. ${ }^{3}$ The variations could be in the form of complete absence, insertion site variation, multiple muscle bellies, different location of the muscle belly, and so on. ${ }^{4}$

The variation highlighted in our case report is the abnormal passage of tendon through the carpal tunnel. As per the proposed classification by Georgiev, ${ }^{5}$ the variation was type III variation. In our case, the tendon instead of lying anterior to the roof of the carpal tunnel, traveled through the carpal tunnel lying superomedial to the nerve ( $\mathbf{- F i g}$. 3 ). It therefore could be a contributory factor for causing the median nerve compression. This partial displacement of the tendon in the anteroposterior plane from the palmar aponeurosis and transverse carpal ligament could be explained by histological and developmental studies on the independent origin of the two structures and their different origin. ${ }^{6}$ The reported variation is of importance as a lack of awareness can lead to accidental damage to the median nerve during harvest of the PL tendon.
Fig. 1 Clinical picture showing the presence of the palmaris longus tendon within the carpal tunnel. received

June 19, 2019

accepted after revision

October 4, 2019

published online

December 30, 2019
DOI https://doi.org/

10.1055/s-0039-3400671

ISSN 0970-0358.
(C)2019 Association of Plastic

Surgeons of India
License terms

()(1) $\Theta \circledast$ 


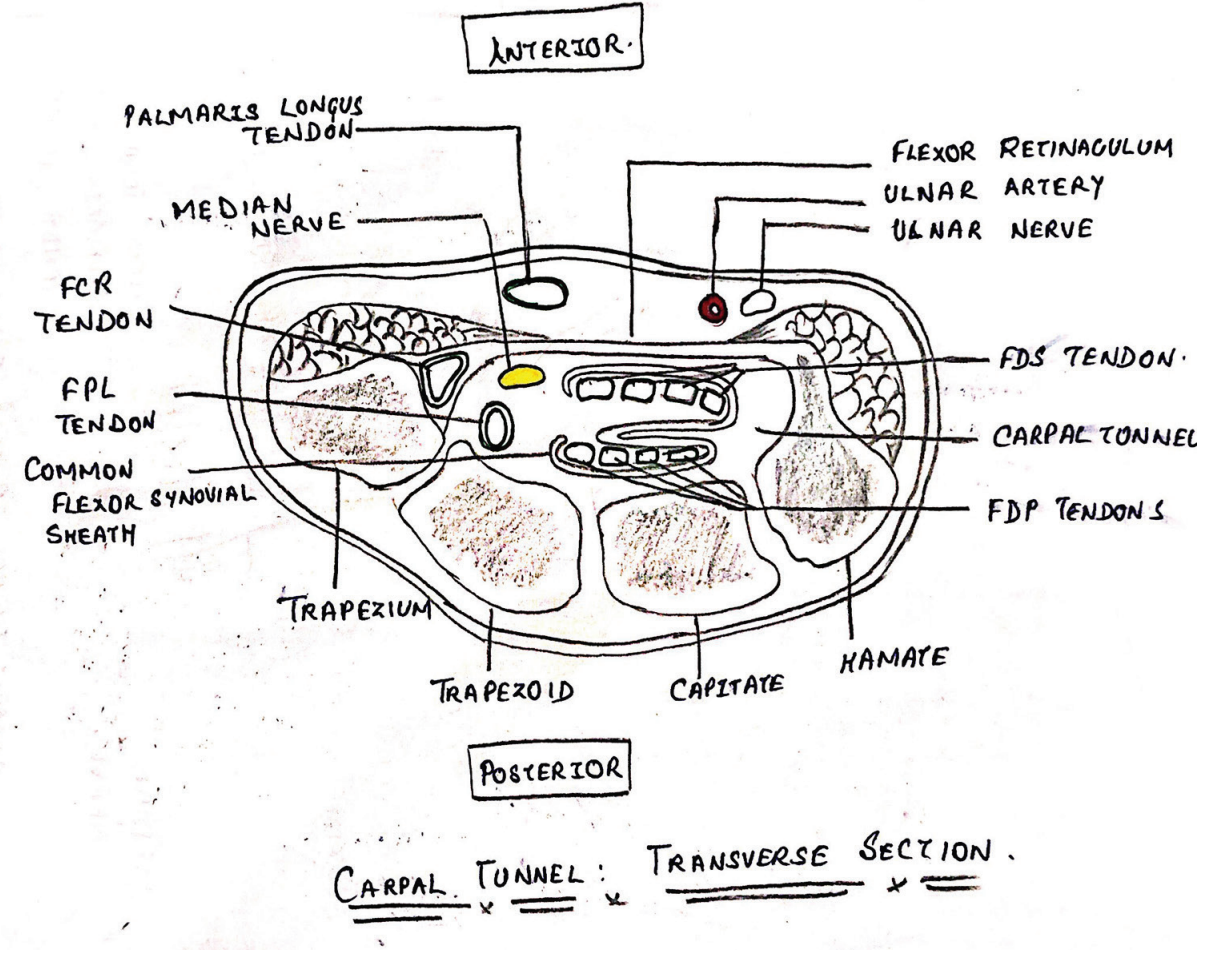

Fig. 2 Line diagram of the transverse section of a normal carpal tunnel depicting the relationship of the palmaris longus tendon to the median nerve FCR, flexor carpi radialis; FDP, flexor digitorum profundus; FDS, flexor digitorum superficialis; FPI, flexor pollicis longus.
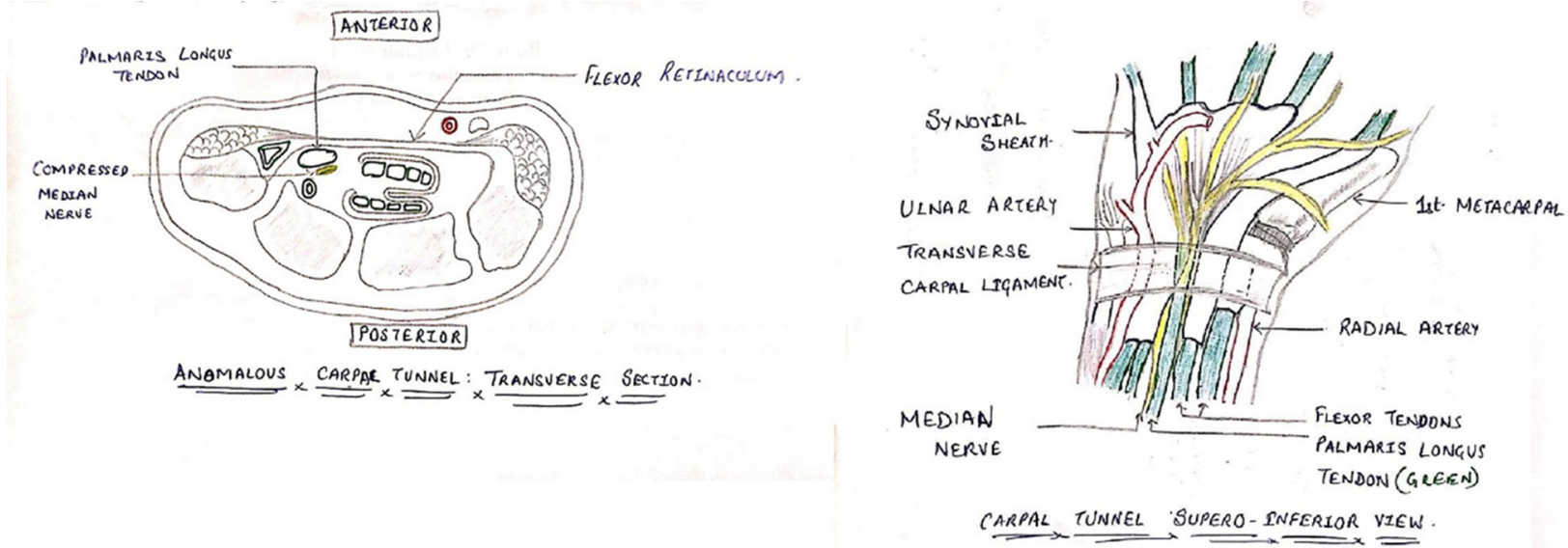

Fig. 3 Line diagrams of the transverse and superoinferior views of the abnormal location of the palmaris longus tendon within the carpal tunnel.

\section{Funding}

None.

\section{Presentation at a Meeting}

None.

\section{Conflict of Interest}

None.

\section{Acknowledgment}

None.

\section{References}

1 Yoshida A, Okutsu I, Hamanaka I. Is complete release of all volar carpal canal structures necessary for complete decompression in endoscopic carpal tunnel release? J Hand Surg Eur Vol 2007;32(5):537-542
2 Standring S. Gray's Anatomy: The Anatomical Basis of Clinical Practice. 40th ed. London: Elsevier Health Sciences; 2008:847

3 Reimann AF, Daseler EH, Anson BJ, Beaton LE. The palmaris longus muscle and tendon. A study of 1600 extremities. Anat Rec 1944;89(4):495-505

4 Bergman RA, Afifi AK, Miyauchi R. Palmaris Longus. Illustrated Encyclopedia of Human Anatomic Variation: Opus I: Muscular System. https://www.anatomyatlases.org/AnatomicVariants/MuscularSystem/Text/P/03Palmaris.shtml. Accessed August 15, 2019

5 Georgiev GP. Palmaris longus muscle variants: well known, what's new? Int J Anat Var 2019;12(1):1

6 Caughell KA, McFarlane RM, McGrouther DA, Martin AH. Developmental anatomy of the palmar aponeurosis and its relationship to the palmaris longus tendon. J Hand Surg Am 1988;13(4):485-493 